\title{
A dispositional approach to psychological climate: Relationships between interpersonal harmony motives and psychological climate for communication safety
}

\begin{abstract}
This study examined the dispositional antecedents of a climate at the individual level, psychological climate for communication safety. The impact of two interpersonal harmony motives, harmony enhancement and disintegration avoidance, on psychological climate for communication safety, innovative performance, and the moderated mediated processes associated with job autonomy were examined in a survey study in China. Results showed that harmony enhancement was positively related to innovative performance through psychological climate for communication safety. Moreover, job autonomy moderated the relationship between harmony motives and psychological climate for communication safety. Harmony enhancement was more strongly associated with psychological climate for communication safety when job autonomy was low. The relationship between disintegration avoidance and psychological climate for communication safety was positive when job autonomy was high, but negative when job autonomy was low. Conditional indirect effects consistent with these interaction effects were also found.
\end{abstract}

Keywords: harmony, psychological climate, communication safety, job autonomy, innovative performance 


\section{A dispositional approach to psychological climate: Relationships between interpersonal harmony motives and psychological climate for communication safety}

Many business organisations have realized the importance of creating an engaging and motivating environment to help employees fully unfold their potential (e.g., Pfeffer, 1994; Shalley et al., 2000). However, employees do not respond to the work environment mechanically, and their perception and interpretation of the environment are crucial in shaping their attitudinal and behavioural responses (James et al., 1978). For instance, a work environment designed to be motivating may not show the intended effects because employees do not perceive the environment as motivating (e.g., Deci et al., 1999). To address this issue, there has been considerable research in the past several decades on the role and dynamics of psychological climate - defined as 'the meanings that people impute to their jobs, co-workers, leaders, pay, performance expectations, opportunities for promotion, equity of treatment, and the like' (James et al., 2008: 6). Psychological climate also has important practical implications, as it is related to a variety of major work outcomes, such as organisational commitment, job satisfaction, and performance (Carr et al., 2003; Parker et al., 2003). It is important to note that we are concerned with processes at the individual level, and research on organisational climate (Schneider et al., 2011), which conceptualizes climate as a property of an organisation, is not our focus.

Despite the well-documented importance of psychological climate, our knowledge of its antecedents is surprisingly limited. This gap is problematic because a theory of psychological climate is incomplete without a clear understanding of the factors that shape its formation. Indeed, Parker et al. (2003: 408) recommended that 'clarifying the origins of psychological climate perceptions would help to clarify the specific mechanisms by which perceptions of the work environment influence individual outcomes.' The limited research on the antecedents of psychological climate has primarily focused on situational factors, such as 
supportive supervisor, rewarding co-worker relationships, and high-performance human resource practices (e.g., May et al., 2004; Wei et al., 2010), which are conceptualized as cues for drawing inferences about the nature of a workplace. This line of work, while important, does not consider the possibility that people exhibit some degree of across-situation consistency in the perception of psychological climate because they tend to confirm what they are prepared to see (Snyder and Ickes, 1985). For example, some employees complain vehemently about their work environment even if many other employees perceive the same environment as attractive (Grensing-Pophal, 2001). Situational factors are not the only antecedents of psychological climate, as Brown and Leigh (1996: 359) suggested that 'psychological climate is likely to result from individual differences among employees, from differences in situations (i.e. features of organizational environments), as well as from the interaction between the person and situation.' The lack of research on dispositional antecedents of psychological climate limits the formulation of evidence-based intervention strategies to mitigate the problem that employees may hold a negative psychological climate not because of the environment, but because of their individual orientations.

The lack of dispositional research on psychological climate is disturbing because the extant literature explicitly acknowledges the influence of individual differences in shaping the perception of work environments. James and his colleagues (James et al., 1978; James and James, 1989; James et al., 1990) have proposed a comprehensive framework for psychological climate. While the focus on situational antecedents of psychological climate in prior research is consistent with this framework, dispositional factors can be antecedents of psychological climate in this framework. James and Jones (1980: 103) proposed that 'individual characteristics ... are directly and causally linked to job perceptions.' According to James and his colleagues, psychological climate, as an individual attribute, takes on personal meaning for employees through a process of valuation, in which people selectively attend to, 
interpret, and remember psychologically meaningful elements based on their personal values. Consequently, employees exhibit stable tendencies in perceiving their work environments. Although the values and the valuation process are affected by contextual factors, the role of dispositional factors in shaping psychological climate cannot be ignored (James et al., 1990). Indeed, there is considerable evidence showing that people's dispositions affect how they perceive and interpret an environment (Caspi and Roberts, 1999). For instance, in a study of twins, Hershberger et al. (1994) found a significant genetic component for psychological climate for support, which clearly underscores the influence of dispositional antecedents of psychological climate. More directly, conscientiousness, openness to experience, and agreeableness were recently found to relate positively to psychological climate for service (Auh et al., 2011).

A major objective of the present research is to respond to James et al.'s (1978) long standing but still insufficiently addressed call to 'explore further the role of person variables in climate perceptions' (p. 791). Many different types of psychological climate may be studied, and we focus on psychological climate for communication safety, which is defined as the perception of a work environment 'characterized by support, openness, trust, mutual respect, and risk taking' (Gibson and Gibbs, 2006: 462). We justify this choice by arguing that communication is critical to organisational success, and Kitchen and Daly (2002) even proposed that supportive communication is the most important factor for the existence of an organisation. Communication promotes the flow of vital information for positive interpersonal interactions, and poor communication can result in conflict and other negative outcomes. People need to appraise the safety level of the communication climate of their environment, so that they can adjust their communicative and other social behaviours accordingly. Thus, it is important to study psychological climate for communication safety, because this psychological climate helps employees establish effective interactions with other 
organisational members.

Which dispositional factors are related to psychological climate for communication safety? Given that this psychological climate is concerned with the belief that the work environment is supportive and open to diverse views, individual differences relevant to the handling of conflicting and dissenting opinions are appropriate antecedents. Leung and his colleagues (Leung, 1997; Leung and Brew 2009; Leung et al., 2011; Leung et al., 2002) have identified two motives of interpersonal harmony, which are concerned with orientations towards how interpersonal disagreement and transgression should be managed. Harmony enhancement refers to an active approach to different opinions and disagreements by 'engaging in behaviors presumed to strengthen the relationships among the interactants,' whereas disintegration avoidance refers to a passive approach to interpersonal disagreement by 'avoiding actions that will strain a relationship and lead to its weakening and dissolving' (Leung, 1997: 644). In other words, people endorsing harmony enhancement are positive towards diversity of views as it helps to develop mutually beneficial relationships, while people endorsing disintegration avoidance tend to view different opinions and disagreements as problems that may disrupt a relationship and hurt their self-interest. The conceptual linkage between harmony motives and attitude towards diversity of views renders harmony motives appropriate antecedents for psychological climate for communication safety.

Psychological climate is predictive of many individual outcomes (James et al., 1978). This paper focuses on a highly desirable employee behaviour - innovative performance, as climate may channel and direct both attention and activities towards innovation (e.g., Amabile, 1988; Scott and Bruce, 1994). Gibson and Gibbs (2006) have theorized and confirmed that team-level communication safety (also known as psychologically safe communication climate) is related to high team innovation because this climate encourages speaking up, raising differences for discussion, initiating personal and informal 
communication, and being open to others' ideas and perspectives. We argue that their reasoning is not restricted to the team context, and psychological climate for communication safety is conducive to individual innovative performance, defined as the intentional generation, promotion, and realization of new ideas (Janssen, 2000). The generalization of the argument of Gibson and Gibbs (2006) to the individual level is important as Drazin et al. (1999: 288) argued that 'The level of generalization is important because it specifies the focal unit to which the theoretical and empirical statements of the research apply.' Integrating the preceding arguments, the effects of harmony motives on innovative performance should be mediated by psychological climate for communication safety.

Finally, to provide further evidence for the proposed relationships between harmony motives and psychological climate for communication safety, we test how these relationships are moderated by a contextual variable. This feature of our design is in line with the proposal that psychological climate is 'a function of both person variables and $\mathrm{P} \times \mathrm{S}$ interactions' (James et al., 1979: 565). Many moderators may be considered, but we reason that contextual variables that have implications for the importance of communication safety are appropriate. We identify job autonomy, defined as 'the degree to which the job provides substantial freedom, independence, and discretion to the individual in scheduling the work and determining the procedures to be used in carrying it out' (Hackman and Oldham, 1976: 258), as an important contextual factor that moderates the influences of harmony motives on psychological climate for communication safety. Our logic is that when people have higher job autonomy, they have more freedom to make job-relevant decisions and initiate task actions. In general, a sense of personal control tends to reduce the impact of people's dispositional tendencies on how they perceive the environment (e.g. Fiske, 1993). This logic provides the basis for the argument, to be elaborated below, that job autonomy can moderate the effects of the two harmony motives on psychological climate for communication safety. 
To sum up, the research contributes to the literature on the antecedents of psychological climate by extending beyond situational factors and providing the impetus to develop a more complete theoretical framework by the inclusion of dispositional antecedents. On the applied side, it is important to understand how psychological climate is rooted in people's personal orientations for developing effective intervention strategies to promote positive psychological climate to achieve organizational goals. More specifically, our research develops a model based on prior theorizing of psychological climate (e.g., James et al., 1978; James et al., 1979; James et al., 2008) to shed light on how two interpersonal orientations, the two harmony motives, influence psychological climate for communication safety and innovative performance, and how the effects of the harmony motives are moderated by job autonomy. The model, which involves complex mediation and moderation effects, provides convincing support for the dispositional approach to psychological climate, and contributes to the development of a fuller, interactionist theory for psychological climate for communication safety. The research also establishes the two harmony motives as important interpersonal orientations by delineating their effects on innovative performance through psychological climate for communication safety, and lays the foundation for developing a theory of harmony motives. See Figure 1 for the research model proposed.

INSERT FIGURE 1 ABOUT HERE

\section{Theory development and hypotheses}

Psychological climate for communication safety depicts the extent to which employees perceive the environment as safe for open communication (Gibson and Gibbs, 2006). Employees feel comfortable interacting and communicating with other colleagues as they perceive that these colleagues will not reject, embarrass, or punish others based on their opinions. In other words, this psychological climate is mainly concerned with interpersonal 
consequences that an individual expects from engaging in communication-related behaviours. Psychological climate for communication safety is relationally oriented and should be affected by dispositional variables that are concerned with the way individuals orient towards their interpersonal relationships and structure their interpersonal behaviours. Harmony motives as individual differences reflect the way individuals handle their interpersonal interactions, and as such these variables should have bearing on how people perceive the communication safety of their immediate environment.

Harmony motives and psychological climate for communication safety

The dualistic model of interpersonal harmony proposes two dispositional orientations regarding how individuals manage their social interactions (Leung, 1997; Leung and Brew, 2009; Leung et al., 2011; Leung et al., 2002). Harmony enhancement reflects the tendency to promote a mutually beneficial relationship and the active engagement in behaviours or actions that promote this goal. In contrast, people high on disintegration avoidance focus on the negative consequences of a strained relationship and avoid actions or events that may hurt interpersonal relationships to protect their self-interest. These two individual orientations have been validated in China and Australia (Leung et al., 2011), as well as in Singapore (Lim, 2009). Across these three cultural groups, harmony enhancement is related to the conflict style of integrating or problem solving, while disintegration avoidance, conflict avoidance. This pattern of findings supports the argument that people high on harmony enhancement engage in open discussion and a frank exchange of views to identify common ground for promoting a positive relationship, whereas people high on disintegration avoidance avoid actions that may strain a relationship, such as criticisms, objections, and confrontation. Leung et al. (2011) suggested that harmony motives are especially useful for predicting outcome variables that are relational in nature, such as the willingness to work together.

According to James et al. (1978), individuals synthesize selected details and stimuli 
gleaned from an environment and evaluate them based on abstract generalizations about situations developed from prior experience to form a psychological climate. The subjective processes involved give rise to variations across individuals, as 'different types of individuals will be attentive to different aspects of their environments in formulating perceptions of psychological influence' (James et al., 1979: 565-566). Following this theorizing, we propose that harmony enhancement is conducive to psychological climate for communication safety, which reflects an individual's perception of an open atmosphere that encourages honest exchange of opinions and views (Gibson and Gibbs, 2006). People who embrace harmony enhancement desire to build long-term positive relationships with others (Leung et al., 2002). They are more likely to attend to and recognize the opportunities for joint gains and collaboration, and view confrontations, debates, and disagreements not as signs of deteriorating relationships, but as actions necessary for arriving at mutually beneficial relationships. Thus, they tend to perceive social interactions as benign and potentially beneficial, and communication as positive and safe.

In contrast, people high on disintegration avoidance are concerned about protecting their self-interest and hence are vigilant in avoiding potentially negative exchanges. They are sensitive about potential threats to interpersonal relationships and negative reactions of other social actors. Open communication about problems and viewpoints is a double-edged sword, and may lead to negative repercussions from other people (Morrison and Milliken, 2000). Contradicting the views of other people and challenging their positions may cause heated debates and conflict, which may damage the relationship with them. We therefore propose that people who endorse disintegration avoidance are more sensitive about the potential risk of communication and the conflict that it may spur. Thus, they tend to perceive social interactions as risky and potentially harmful, leading to a negative relationship between disintegration avoidance and psychological climate for communication safety. The following 
hypotheses are proposed:

Hypothesis 1a: Harmony enhancement is positively associated with psychological climate for communication safety.

Hypothesis $1 \mathrm{~b}$ : Disintegration avoidance is negatively associated with psychological climate for communication safety.

\section{Psychological climate for communication safety as a mediation mechanism}

According to Gibson and Gibbs (2006: 462), team-level communication safety 'facilitates innovation because it involves speaking up, raising differences for discussion, engaging in spontaneous and informal communication, providing unsolicited information, and bridging differences by suspending judgment, remaining open to other ideas and perspectives, and engaging in active listening.' People who engage in innovative attempts typically need to raise new, unconventional ideas, explore new directions through trial and error, and request the cooperation of other people, all of which may result in embarrassing or threatening reactions from others. Gibson and Gibbs emphasized the key role of communication safety in driving team innovation because in a safe communication environment, team members would spontaneously engage in communication-related behaviours that are conductive to innovation.

Following the theorizing of Gibson and Gibbs (2006), we propose that psychological climate for communication safety facilitates individual innovative performance. At the individual level, people who feel safe about communication are more likely to actively engage in frequent, spontaneous, informal, and direct information exchange with others, thus promoting innovation through the exposure to diverse ideas and perspectives (Edmondson, 2003). They are more likely to receive critical remarks and suggestions about their ideas from co-workers, and as a result develop more innovative ideas. Psychological climate for communication safety also helps create trust (Gibson and Cohen, 2003) and reduce 
perception of risk (Dutton, 1999), thus encouraging people to develop and promote innovative ideas. This analysis suggests a positive relationship between psychological climate for communication safety and innovative performance.

Hypothesis 2: Psychological climate for communication safety is positively associated with innovative performance.

We predict significant relationships between harmony motives and psychological climate for communication safety, and a significant relationship between this psychological climate and innovative performance. Together, these predictions suggest a mediation model in which harmony motives indirectly affect innovative performance through psychological climate for communication safety. This proposition is in line with the general principle of psychological climate theory (e.g., James and James, 1989) that individuals form cognitive representations of an environment based on their own personal values or internal standards and then respond to these perceptions, but 'not the objective situation per se' (James et al., 1978: 786). Because there is no theoretical ground to expect psychological climate for communication safety to be the only mediating mechanism between harmony motives and innovative performance, the mediating effect is assumed to be partial.

Hypothesis 3a: Psychological climate for communication safety mediates the relationship between harmony enhancement and innovative performance. Hypothesis 3b: Psychological climate for communication safety mediates the relationship between disintegration avoidance and innovative performance.

\section{The moderating role of job autonomy}

James and his colleagues (1978) suggested that the influence of individual dispositions may be enhanced or mitigated by situational factors. For example, they proposed that the degree of ambiguity and uncertainty in an environment may moderate the impact of dispositions on the perception of the environment. Following their perspective, we reason that 
a contextual variable that has implications for the importance of communication safety can moderate the effects of the two harmony motives. That is, harmony motives would have different impact on psychological climate for communication safety as a function of this contextual variable.

We identify job autonomy as an appropriate moderator because it is a core job characteristic that reflects how much discretion and control individuals have over their own work. When people have high job autonomy, their work outcomes primarily depend on their own efforts, initiatives, and decisions (Hackman and Oldham, 1976). It follows that job autonomy affects the extent to which people can control the success and failure in their jobs. Although job autonomy is concerned with task procedures, it has social implications because it affects the extent to which other co-workers and their actions are important (Langfred, 2000). Because job autonomy reduces the extent of external control (Spreitzer, 1995), the controllability provided by job autonomy should lower the attention directed at co-workers. It is important to note that we do not argue that job autonomy eliminates the need to get along with co-workers and fit into an organization. The main thrust of our argument is that job autonomy will reduce people's need to attend to other people and their reactions, which is consistent with Langfred's argument (2000: 569) that "as individuals exert more control over the scheduling and implementation of their own tasks, there will be less interaction between group members". Indeed, Langfred found that individual autonomy was negatively related to group cohesiveness.

We theorize that job autonomy can mitigate the positive effects of harmony motives on psychological climate for communication safety. Job autonomy gives employees freedom and independence to perform a task (Morgeson et al., 2005), with less worry about the repercussions of negative reactions and actions of their co-workers. The positive effect of harmony enhancement on psychological climate for communication safety is driven by a 
lower concern about the potential risk of the disruption of a relationship. When job autonomy is high, even those who lack an authentic affinity for interpersonal harmony become less worried about the negative potential of expressing their opinions and views. In this context, their perception of lower interpersonal risk results in higher psychological climate for communication safety. Another way to put it is that high job autonomy acts as a substitute for harmony enhancement in influencing psychological climate for communication safety.

In a similar vein, we theorize that job autonomy can attenuate the relationship between disintegration avoidance and psychological climate for communication safety, because the self-control provided by job autonomy reduces the worry and fear associated with negative interpersonal relationships. Although people high on disintegration avoidance worry about negative consequences and backlashes of a strained relationship (Leung et al., 2011), job autonomy gives them the assurance that the negative relationship matters less and has less negative consequences because their work outcomes depend more on themselves (Pierce et al., 1989). When job autonomy is high, people endorsing disintegration avoidance are therefore less wary about the negative consequences of disruptive communication, leading to less negative psychological climate for communication safety. Moreover, as people high in disintegration avoidance tend to avoid conflict (Leung et al., 2011), they are unlikely to reap the beneficial effects of conflict over task-relevant ideas, strategies, policies, and procedures (de Dreu, 2010). The freedom provided by high job autonomy may reduce their anxiety associated with this type of conflict, thus resulting in a more positive psychological climate for communication safety and better innovative performance. Two moderating hypotheses are proposed:

Hypothesis 4a: Job autonomy moderates the relationship between harmony enhancement and psychological climate for communication safety, such that the positive relationship becomes weaker when job autonomy is higher. 
Hypothesis $4 b$ : Job autonomy moderates the relationship between disintegration avoidance and psychological climate for communication safety, such that the negative relationship becomes weaker when job autonomy is higher.

Cumulatively, the above predictions suggest a moderated mediation model (i.e., Model 2 in Preacher et al., 2007), in which the paths linking interpersonal harmony to innovative performance through psychological climate for communication safety are moderated by job autonomy. We propose the following moderated mediation hypotheses:

Hypothesis 5a: The indirect relationship between harmony enhancement and innovative performance via psychological climate for communication safety is moderated by job autonomy, such that the indirect relationship becomes weaker when job autonomy is higher.

Hypothesis 5b: The indirect relationship between disintegration avoidance and innovative performance via psychological climate for communication safety is moderated by job autonomy, such that the indirect relationship becomes weaker when job autonomy is higher.

\section{Method}

\section{Participants and procedures}

Data were collected from a large urban University in China. A total of 150 questionnaires were distributed to its part-time MBA students with full-time employment, and 135 respondents returned the completed questionnaires ( $90 \%$ response rate). We also solicited the participation of firms in an industrial park near this University based on a list of companies that had cooperated with the University. A total of 260 questionnaire-sets were distributed to these firms, and 86 sets were returned (33\% response rate). All participants were instructed to complete a questionnaire for subordinates and ask their immediate supervisors to complete a questionnaire for supervisors. Each supervisor evaluated only one 
employee. These participants came from a variety of industries including manufacturing, trading, and information technology. This sampling strategy provided variation in the variables of interest and minimized contextual influence associated with a particular firm or industry (Rousseau and Fried, 2001). We tested for differences between the two samples regarding the key variables: harmony enhancement, disintegration avoidance, psychological climate for communication safety, job autonomy, and innovative performance $(\mathrm{t}(191)=.51$, $n s, \mathrm{t}(191)=1.86, n s, \mathrm{t}(191)=.05, n s, \mathrm{t}(191)=.61, n s$, and $\mathrm{t}(191)=.32, n s$, respectively $) ;$ and demographic variables: gender, age, tenure, and education $(\mathrm{t}(186)=.93, n s, \mathrm{t}(186)=.32, n s$, $\mathrm{t}(191)=.27, n s, \mathrm{t}(184)=.67, n s$, respectively). No significant difference was found, and we collapsed the data into one sample. Twenty-eight sets of questionnaires were excluded due to a large amount of missing data or irregular patterns indicative of careless responses, resulting in 193 valid sets. Background information for the final sample was as follows: $54 \%$ were male; most were relatively young (93\% younger than 39 ); $29 \%$ had a tenure of less than 1 year, $43 \%$ 1-3 years, 24\% 4-6 years, 3\% 7-8 years, and 1\% did not indicate their tenure; $28 \%$ had a lower than university degree, $65 \%$ a university degree, $3 \%$ a graduate degree, and $4 \%$ did not indicate their education level. Regarding the supervisors, $64 \%$ were male; $25 \%$ were line managers, $49 \%$ departmental managers, $12 \%$ senior managers, and $14 \%$ did not indicate their rank.

\section{Measures}

Except for the harmony scales, all items were originally developed in English and translated into Chinese with a back-translation procedure (Brislin, 1986). To avoid common method bias, supervisors assessed subordinates' innovative performance, and subordinates reported on other variables.

Harmony motives. The harmony scales developed by Leung et al. (2011) include 12 items for harmony enhancement and six items for disintegration avoidance. The coefficient 
alphas for the two harmony motives were not large in previous research, especially for disintegration avoidance (e.g., .63 in Lim, 2009). Therefore, we invited a group of part-time MBA students who did not participate in the survey to generate new items to improve the coverage of the harmony measures. They were provided with the definitions of harmony enhancement and disintegration avoidance, and then asked to describe experiences and observations related to these two harmony motives. Their relevant responses were collated for developing new harmony items. We added four new items to the harmony enhancement scale and three items to the disintegration avoidance scale (See the Appendix for all items). Responses were given on Likert-type scales ranging from 1 (Strongly Disagree) to 5 (Strongly Agree). The Cronbach alphas for harmony enhancement and disintegration avoidance were .68 and .73 .

Psychological climate for communication safety. The three items for measuring psychologically safe communication climate developed by Gibson and Gibbs (2006) were used. Participants were asked to indicate the extent to which their companies were characterized by the items, and sample items included 'Members are able to say what they think' and 'When there's a problem, members can talk about it.' Likert-type scales ranging from 1 (Not at All) to 5 (To a Very Great Extent) were used (Cronbach's $\alpha=.71$ ).

Job autonomy. We used Hackman and Oldham's (1975) three-item scale, and a sample item was 'The job gives me almost complete responsibility for deciding how and when the work is done.' Responses were given on Likert-type scales ranging from 1 (Strongly Disagree) to 7 (Strongly Agree). The Cronbach alpha was .72.

Innovative performance. Janssen's (2001) nine-item scale was used to measure innovative performance. Sample items included 'This employee creates new ideas for improvements' and 'This employee mobilizes support for innovative ideas.' Seven-point Likert-type scales $(1=$ Never, 7 = Always $)$ were used, and the Cronbach alpha was .86. 
Control variables. We controlled for gender, age, organisation tenure, and education, as previous studies have shown that these variables are related to innovative performance (e.g., Janssen, 2001; Janssen and van Yperen, 2004; Scott and Bruce, 1994). Data source (i.e. university or industrial park) was also included to control for its potential influence.

\section{Data analyses}

We first examined a simple mediation model, and then conducted hierarchical multiple regression analyses for the moderation hypotheses. Finally, we adopted Preacher and his colleagues' (2007) general framework to test for moderated mediation effects. Prior to the analyses, all continuous variables were mean-centred (Aiken and West, 1991).

Tests of mediation. We hypothesized that the relationship between harmony motives and innovative performance would be transmitted by psychological climate for communication safety. Traditionally, such mediating effects are tested by Baron and Kenny's (1986) multistep approach, but this approach is widely regarded as problematic (e.g.

LeBreton et al., 2009; Mackinnon et al., 2002). In particular, there is consensus that the direct effect of the independent variable on the dependent variable need not be significant (e.g. Mackinnon et al., 2007; Shrout and Bolger, 2002; Zhao et al., 2010). The conditions for mediation are: (a) the independent variable must be related to the mediator; (b) the mediator must be related to the dependent variable; (c) when the effects of the independent variable and the mediator are examined simultaneously, the mediator must still be significantly related to the dependent variable (Mackinnon, 2008).

We further evaluated the mediation effects with the $95 \%$ confidence interval (CI) using bias-corrected bootstrapping with 5,000 draws (Preacher and Hayes, 2008). This approach involved computing a CI around indirect effects, and if the CI does not contain zero, significant mediation is established. This approach has the advantage of increasing power with small samples, as well as correcting for violations of the normality assumption (Preacher 
and Hayes, 2004).

Tests of moderation. We used hierarchical multiple regression analyses to test the moderation hypotheses. To examine the nature of the significant interaction effects, we plotted the simple slopes for the relationship between the two harmony motives and psychological climate for communication safety at one standard deviation below and above the mean of job autonomy (Aiken and West, 1991). In addition, we adopted the approach of Preacher et al. (2007) to test whether the indirect effect of harmony motives on innovative performance through the mediator, i.e. psychological climate for communication safety, was conditional on job autonomy. This analysis was conducted with an SPSS macro developed by Preacher et al. (2007), which produced bootstrapped, bias-corrected CIs for examining the significance of conditional indirect effects at different values of the moderator variable. Following Preacher et al. (2007), we operationalized high and low levels of job autonomy as one standard deviation above and below the mean.

\section{Results}

To provide discriminant validity for the five key variables, a confirmatory factor analysis using AMOS 16.0 was conducted (Arbuckle, 2007). We have a complex model, and to reduce the large number of parameters for accurate estimates, we formed three parcels for harmony enhancement, disintegration avoidance, and innovative performance by averaging the highest and the lowest loadings successively (Little et al., 2002). This strategy is commonly adopted in studies with large parameter-to-sample size ratios (e.g. Fuller et al, 2006; Wang and Rode, 2010). The hypothesized five-factor model yielded a good fit, $\chi^{2}(80)$ $=105.35 ; \mathrm{CFI}=.97 ; \mathrm{TLI}=.96 ; \mathrm{RMSEA}=.04$, and was significantly better than the single factor model, $\chi^{2}(90)=803.73 ; \mathrm{CFI}=.19 ; \mathrm{TLI}=.06 ; \mathrm{RMSEA}=.20, \Delta \chi^{2}=698.38, p<.01$.

Means, standard deviations, correlations and reliabilities for all the variables are presented in Table 1. Harmony enhancement was positively related to psychological climate 
for communication safety $(r=.23, p<.01$, Cohen's $d=.47)$, which was positively related to innovative performance ( $r=.15, p<.05$, Cohen's $d=.31)$. However, disintegration avoidance was not related to psychological climate for communication safety $(r=.00, n s$, Cohen's $d=.01$ ). Since gender, age, education, and data source were not significantly associated with any main variables, we did not include them in further analyses following a common practice (e.g. Erdogan and Bauer, 2009).

INSERT TABLE 1 ABOUT HERE

Table 2 shows that harmony enhancement was positively related to psychological climate for communication safety $(\beta=.19, p<.01)$, supporting Hypothesis 1a. However, the relationship between disintegration avoidance and psychological climate for communication safety was not significant $(\beta=.02, n s)$, providing no support for Hypothesis $1 \mathrm{~b}$. This result should be interpreted in light of an interaction effect involving job autonomy reported below.

Hypothesis 2, which states that psychological climate for communication safety is positively related to innovative performance, was supported $(r=.15, p<.05)$. Psychological climate for communication safety was still positively related to innovative performance after controlling for the two harmony motives $(\beta=.14, p<.05)$.

In support of Hypothesis 3a, harmony enhancement showed an indirect effect on innovative performance through psychological climate for communication safety. Results indicated a $95 \%$ CI ranging from .002 to .132, suggesting that psychological climate for communication safety did play a mediating role in the relationship between harmony enhancement and innovative performance. However, Hypothesis $3 \mathrm{~b}$, which states that psychological climate for communication safety mediates the relationship between disintegration avoidance and innovative performance, was not supported $(95 \% \mathrm{CI}=$ $-.027, .042, n s)$. As before, this null finding has to be interpreted in light of the significant 
interaction effect involving job autonomy.

INSERT TABLE 2 ABOUT HERE

Hypothesis 4a states that the positive relationship between harmony enhancement and psychological climate for communication safety would be weaker when job autonomy is high. Results presented in Table 3 indicate that the interaction term between harmony enhancement and job autonomy is significant $(\beta=-.16, p<.05)$. As shown in Figure $2 \mathrm{a}$, the pattern is consistent with the prediction: When job autonomy is high, the relationship between harmony enhancement and psychological climate for communication safety is weaker. Simple slope tests indicated that the association between harmony enhancement and psychological climate for communication safety was positive and significant when job autonomy was low $(\beta=.78$, $p<.01)$, but was not significant when job autonomy was high $(\beta=.06, n s)$.

INSERT TABLE 3 ABOUT HERE

Hypothesis $4 \mathrm{~b}$ states that the negative relationship between disintegration avoidance and psychological climate for communication safety is weaker when job autonomy is high. Consistent with this hypothesis, the interaction effect between disintegration avoidance and job autonomy on psychological climate for communication safety was significant $(\beta=.16, p$ $<.05$ ), supporting the moderating effect of job autonomy (see Table 3 and Figure $2 b$ ). As expected, a simple slope test indicated that the association between disintegration avoidance and psychological climate for communication safety was negative when job autonomy was low (simple slope $\beta=-.18, n s$ ). Unexpectedly, this relationship was positive and approached significance when job autonomy was high (simple slope $\beta=.30, p \leq .07$ ), suggesting a disordinal interaction effect. Although the simple slope tests were not significant, Aiken and West (1991: 20-21) pointed out that 'the significance of the $b_{3}$ coefficient in the overall 
analysis indicates that the regression of $Y$ on $X$ varies across the range of $Z$.' The Coefficient $b_{3}$ refers to the coefficient for the interaction effect between an independent variable $(X)$ and a moderator $(Z)$ on a dependent variable $(Y)$, which in our case is the significant interaction between disintegration avoidance and job autonomy. We therefore conclude that the relationship between disintegration avoidance and psychological climate for communication safety changed significantly from negative to positive as job autonomy increased. Hypothesis $4 \mathrm{~b}$ was partially supported, with an unexpected positive relationship between disintegration avoidance and psychological climate for communication safety when job autonomy was high. This intriguing interaction effect is explored in the discussion.

\section{INSERT FIGURE 2A and 2B ABOUT HERE}

Hypothesis $5 \mathrm{a}$ and $5 \mathrm{~b}$ state that job autonomy moderates the indirect relationship that harmony enhancement and disintegration avoidance have with innovative performance via psychological climate for communication safety. The moderated mediation analyses based on Preacher et al.'s (2007) approach were adopted. When job autonomy was low, the indirect effect of harmony enhancement on innovative performance through psychological climate for communication safety was positive and significant $(B=.11,95 \% \mathrm{CI}=.014, .264)$. When job autonomy was high, the indirect effect of harmony enhancement was not significant $(B=.01$, $95 \% \mathrm{CI}=-.040, .076)$. Therefore, Hypothesis 5a was supported.

When job autonomy was low, the indirect effect of disintegration avoidance on innovative performance was negative, but not significant $(B=-.03,95 \% \mathrm{CI}=-.115, .015)$. When job autonomy was high, however, the indirect effect of disintegration avoidance on innovative performance was positive and significant $(B=.04,95 \% \mathrm{CI}=.001, .120)$. The significant effect supports a moderated mediation, but the pattern is not entirely consistent with Hypothesis 5b, which requires further exploration. 


\section{Discussion}

To demonstrate the importance and utility of the dispositional approach to psychological climate, this paper identifies two harmony motives as the dispositional antecedents of psychological climate for communication safety. As predicted, harmony enhancement is positively related to innovative performance through psychological climate for communication safety. Job autonomy interacts with harmony enhancement to affect psychological climate for communication safety in that the effect of harmony enhancement is attenuated by job autonomy.

Unexpectedly, the relationship between disintegration avoidance and psychological climate for communication safety is not significant due to the disordinal interaction effect between disintegration avoidance and job autonomy. Consistent with our prediction, disintegration avoidance is negatively related to psychological climate for communication safety when job autonomy is low. However, this relationship is positive when job autonomy is high. We speculate that because people with high disintegration avoidance are sensitive about potential gains and losses in social interactions, they understand clearly that when job autonomy is high, their success and failure are shielded from the repercussion of negative relationships. In other words, they are fully aware of the fact that their self-interest is not affected even if they run into communication problems with other people, leading them to perceive more safety in the communication environment. This account is obviously highly speculative and needs to be evaluated in future research.

\section{Theoretical implications for psychological climate for communication safety}

Results of the present study provide insights about the dispositional antecedents of psychological climate for communication safety and psychological climate in general. It is well-known that different individuals may have different perceptions of the same environment (James and Tetrick, 1986), a realization that set off research on psychological 
climate decades ago (James et al., 1978; James and James, 1989; James et al., 1990). The dispositional approach in other domains is well-established, such as job satisfaction (Staw and Ross, 1985), work motivation (Judge and Ilies, 2002), and organisational citizenship behaviour (Organ and Ryan, 1995). Despite the success in other areas, the dispositional approach in psychological climate is ignored, even though the psychological climate literature explicitly recognizes individual variation in the perception of the work environment (James et al., 1978; James and James, 1989; James et al., 1990).

Our study fills this significant gap and extends the traditional focus on contextual antecedents of psychological climate (e.g. Tierney, 1999) by relating two relational individual difference variables (i.e. harmony enhancement and disintegration avoidance) to psychological climate for communication safety. Our results offer support for the dispositional approach to psychological climate as an important future research direction. We note that harmony motives are related to psychological climate for communication safety as both are relational in nature. For psychological climate that is task-focused, different types of dispositional antecedents may be involved. For example, self-efficacy, confidence in one's skills and abilities (e.g. Schmidt and DeShon, 2010), may be related to the formation of task-focused psychological climate such as creativity climate (Amabile et al., 1996) and service climate (Schneider et al., 2005). Future studies should explore specific dispositional antecedents of different types of psychological climate according to their nature.

Equally important, the study contributes to the literature on disposition-job outcome relationships by identifying psychological climate as a mediator of these relationships. Researchers have called attention to probing theoretically-relevant and empirically-tested mechanisms underlying the effects of dispositional variables in work settings (Barrick et al., 2001). Our research adds to this research direction by demonstrating conditional indirect effects of harmony motives on innovative performance through psychological climate for 
communication safety. Other types of psychological climate may also mediate the relationship between dispositional variables and job-related behaviours, a fruitful direction for future research to pursue.

With regard to psychological climate for communication safety, it is important to explore other dispositional antecedents of this psychological climate. Harmony motives are relational constructs, and the other dispositions that have a relational theme may be considered, such as agreeableness (Graziano and Tobin, 2009), need for affiliation (Wiesenfeld et al., 2001), and psychological collectivism (Jackson et al., 2006). With regard to the consequences of psychological climate for communication safety, outcome variables beyond innovative performance can be explored. Given the central role of communication in work life, we expect this psychological climate to have diverse effects. Possible candidates that are related to interpersonal communication include voice behaviour (LePine and Van Dyne, 2001), learning behaviour (Maurer et al., 2003), and conflict behaviour (Rahim, 1985). Theoretical implications for harmony motives

The findings have several important implications for developing a model of interpersonal harmony motives. First, the significant relationships between harmony motives and psychological climate for communication safety suggest that harmony motives may have impact on a variety of outcome variables mediated by this psychological climate. For example, safety perception of the interpersonal environment is related to various relationally oriented outcomes, such as willingness to share knowledge (Siemsen et al., 2009), help seeking (Tynan, 2005), and information sharing (Bunderson and Boumgarden, 2010). Our results suggest that harmony motives are likely to influence these attitudinal and behavioural outcomes through their impact on psychological climate for communication safety. Following this line of reasoning, an interesting possibility is that in addition to psychological climate for communication safety, other relationally oriented perceptions of the work environment, such 
as interactive cooperation climate (Jaw and Liu, 2003), may serve as mediating mechanisms linking harmony motives to a wide range of task outcomes.

Second, the disordinal interaction effect between disintegration avoidance and job autonomy suggests that the effect of this harmony orientation is more complex than originally conceived. This finding contradicts the simplistic association of disintegration avoidance with a heightened tendency to avoid offending others in order to protect self-interest. Our results suggest that the effects of disintegration avoidance are likely to be qualified by variables related to gain-loss calculations. As people high on disintegration avoidance are sensitive to the potential gains and losses that may incur in a given social situation, they may adjust their behaviour according to the context so as to maximize their self-interest. An interesting conjecture is that if in situations where meekness does not protect self-interest, people high on disintegration avoidance may become aggressive. This speculation is supported by the positive correlation between disintegration avoidance and the conflict style of dominating (Leung et al., 2011). Individuals high on this orientation may be particularly influenced by contextual variables that have bearings on gains and losses - an intriguing future research direction.

\section{Practical implications}

The findings have several important practical implications. Many organisations and managers have realized the importance of the work environment, especially for promoting innovative performance. However, the environment per se does not directly influence employee outcomes, but employees' perception of the environment does. The current research shows that psychological climate is influenced by people's dispositional orientations, harmony motives in our case. While managers should strive to provide a positive work environment for their subordinates, they also need to consider management practices to boost desirable employee perception of the work environment such as psychological climate for 
communication safety. Our findings suggest that management should pay attention to individual characteristics such as harmony enhancement and disintegration avoidance, and point to some practical strategies to enhance psychological climate based on the dispositional perspective. For example, if it is important for employees to feel safe about their communication environment, those who are high on harmony enhancement may be targeted in selection. Training may also be provided to enhance harmony enhancement, although the process would be long as it is a relatively stable disposition.

In addition, management needs to pay extra attention to those high on disintegration avoidance as they tend to have negative psychological climate for communication safety when they have low job autonomy. Organisations and supervisors may need to show more support for those holding different opinions and ideas from the majority. If employees high on disintegration avoidance observe that organisations and supervisors do not punish people who communicate freely, they may gradually worry less about the negative consequences of speaking up, and feel safer about the communication atmosphere at work. Again, training may also be provided to lower disintegration avoidance among employees.

\section{Limitations and future research}

Despite the coherent results obtained, this study has some limitations that need to be addressed in future research. First, because the dispositional approach to psychological climate is nascent, we rely on a theoretical perspective of psychological climate rather than a specific theory to guide the development of hypotheses. Following a common practice in early stages of theory development (e.g., Brown and Leigh, 1996; May et al., 2004), we examine the construct definition of psychological climate for communication safety to identify appropriate antecedent, dependent and moderator variables. Future research needs to evaluate the theoretical implications of our findings to confirm the validity of our theorizing.

Future research should also examine how dispositional factors moderate the effects of 
contextual factors on psychological climate, as James et al. (1979) proposed that 'two forms of moderation were involved, namely moderation due to differences among individuals and moderation due to differences among situations' (p. 569). The current research highlights the dispositional approach, and we treat harmony motives as independent variables and job autonomy as a moderator. However, it is theoretically possible that dispositional factors can moderate the way an environmental factor is perceived (James et al., 1990), and harmony motives may moderate the effects of contextual variables on psychological climate. In fact, dispositional variables often function as both antecedents and moderators in the extant literature. For example, conscientiousness is generally recognized as the single best dispositional antecedent of work-related performance (Barrick et al., 2001), but researchers also conceptualize it as a moderator (e.g., Fong and Tosi, 2007; Taylor et al., 2012). It is therefore important to examine the moderating effects of dispositional variables, including harmony motives, in future research on psychological climate ${ }^{1}$.

Second, the cross-sectional design of the study does not take into account the hypothesized causal sequence (Bono and McNamara, 2011) and raises questions about the direction of causality. Although the predictions are justified theoretically, we cannot rule out the possibility of other causal directions ${ }^{2}$. Harmony motives are relatively stable dispositional factors, but they may temporarily shift in reaction to environmental influences. It is plausible that people who experience better psychological climate for communication safety may become less concerned about protecting their self-interest and therefore show lower disintegration avoidance. In line with this logic, Dragoni (2005) proposed that psychological climate may signal and compel individuals to adopt a particular form of state goal orientation. However, harmony motives are relatively stable orientations that affect behaviours across diverse domains such as family, social activities, and work, and we believe that a specific work climate is unlikely to alter such broad orientations in a permanent way. Moreover, 
harmony motives are unlikely to mediate the effect of psychological climate for communication safety because of the lack of empirical support. Following a common practice to reduce ambiguity in causal ordering in cross-sectional designs (e.g., Bizer et al., 2012; Parzefall and Kuppelwieser, 2012), we tested a model with an alternative causal order and found that harmony motives were not able to mediate the relationship between psychological climate for communication safety and innovative performance. Nonetheless, we encourage the use of longitudinal studies in future research for a rigorous test of the causal directions implied in our theorizing.

Third, we measured innovative performance solely from the perspective of supervisors. Although supervisory ratings are the most widely used measure of individual innovative performance, it is useful to consider other measures in future research, such as objective performance data and peer evaluation.

Finally, like most studies in the literature, this study was conducted in a single nation, namely, China, which raises the issue of generalizablity. The relationships reported may be qualified by societal culture. Leung et al. (2011) found that although the relationship between harmony enhancement and conflicts styles is quite similar across Chinese and Australians, disintegration avoidance was positively related to compromising and obliging for Chinese but not for Australians. Although culture may moderate the strengths of the relationships reported in our study, we believe that the pattern of results obtained should generalize to other cultural contexts because our theorizing is not tied to any cultural dynamics. In addition, our finding on the direct relationship between psychological climate for communication safety and innovative performance is consistent with relevant results observed in the West (Gibson and Gibbs, 2006). Nonetheless, it is useful to evaluate our findings in other cultural contexts.

To conclude, the current study presents a new line of research on psychological climate by focusing on its dispositional antecedents and linking interpersonal harmony to 
innovative performance through psychological climate for communication safety. The research also highlights job autonomy as a boundary condition for the effects of harmony motives on psychological climate for communication safety. Our theorizing and findings suggest several fruitful directions for future research. 


\section{References}

Aiken LS and West SG (1991) Multiple Regression: Testing and Interpreting Interactions. Newbury Park, CA: Sage Publications.

Amabile TM (1988) A model of creativity and innovation in organizations. Research in Organizational Behavior 10: 123-167.

Amabile TM, Conti R, Coon H, Lazenby J and Herron M (1996) Assessing the work environment for creativity. Academy of Management Journal 39(5): 1154-1184.

Arbuckle JL (2007) Amos 16.0 User's Guide. Chicago, Ill: SPSS Inc.

Auh S, Menguc B, Fisher M and Haddad A (2011) The contingency effect of service employee personalities on service climate: Getting employee perceptions aligned can reduce personality effects. Journal of Service Research 14(4): 426-442.

Baron RM and Kenny DA (1986) The moderator-mediator variable distinction in social psychological research: Conceptual, strategic, and statistical considerations. Journal of Personality and Social Psychology 51(6): 1173-1182.

Barrick MR, Mount MK and Judge TA (2001) The FFM personality dimensions and job performance. Meta-Analysis of meta-analyses. International Journal of Selection and Assessment 9(1/2): 9-30.

Bizer GY, Hart J and Jekogian AM (2012) Belief in a just world and social dominance orientation: Evidence for a mediational pathway predicting negative attitudes and discrimination against individuals with mental illness. Personality and Individual Differences 52(3): 428-432.

Bono JE and McNamara G (2011) Publishing in AMJ-Part 2: Research design. Academy of Management Journal 54(4): 657-660.

Brislin RW (1986) The wording and translation of research instruments. In Lonner WJ and Berry JW (eds) Field Methods in Cross-Cultural Research. Beverly Hills, CA: Sage 
Publications, 137-164.

Brown SP and Leigh TW (1996) A new look at psychological climate and its relationship to job involvement, effort, and performance. Journal of Applied Psychology 81(4): 358-368.

Bunderson JS and Boumgarden P (2010) Structure and learning in self-managed teams: Why 'bureaucratic' teams can be better learners. Organization Science 21(3): 609-624.

Carr JZ, Schmidt AM, Ford JK and DeShon RP (2003) Climate perceptions matter: A meta-analytic path analysis relating molar climate, cognitive and affective states, and individual level work outcomes. Journal of Applied Psychology 88(4): 605-619.

Caspi A and Roberts BW (1999) Personality continuity and change across the life course. In Pervin LA and John OP (eds) Handbook of Personality: Theory and Research, 2nd edn. New York: Guilford Press, 300-326.

de Dreu CKW (2010) Conflict at work: Basic principles and applied issues. In Zedeck S (ed) APA Handbook of Industrial and Organizational Psychology. Washington: APA Press, 461-493.

Deci EL, Koestner R and Ryan RM (1999) A meta-analytic review of experiments examining the effects of extrinsic rewards on intrinsic motivation. Psychological Bulletin 125(6): $627-668$.

Dragoni L (2005) Understanding the emergence of state goal orientation in organizational work groups: The role of leadership and multilevel climate perceptions. Journal of Applied Psychology 90(6): 1084-1095.

Drazin R, Glynn MA and Kazanjian RK (1999) Multilevel theorizing about creativity in organizations: A sensemaking perspective. Academy of Management Review 24(2): 286-307.

Dutton WH (1999) Society on the Line: Information Politics in the Digital Age. Oxford: 
Oxford University Press.

Edmondson AC (2003) Speaking up in the operating room: How team leaders promote learning in interdisciplinary action teams. Journal of Management Studies 40(6): 1419-1452.

Erdogan B and Bauer TN (2009) Perceived overqualification and its outcomes: The moderating role of empowerment. Journal of Applied Psychology 94(2): 557-565.

Fiske ST (1993) Controlling other people: The impact of power on stereotyping. American Psychologist 48(6): 621-628.

Fong EA and Tosi HL (2007) Effort, performance, and conscientiousness: An agency theory perspective. Journal of Management 33(2): 161-179.

Fuller JB, Hester K, Barnett T, Frey L, Relyea C, and Beu D (2006) Perceived external prestige and internal respect: New insights into the organizational identification process. Human Relations 59(6): 815-846.

Gibson CB and Cohen SG (2003) Virtual Teams That Work: Creating Conditions for Virtual Collaboration Effectiveness. San Francisco: Jossey-Bass.

Gibson CB and Gibbs JL (2006) Unpacking the concept of virtuality: The effects of geographic dispersion, electronic dependence, dynamic structure, and national diversity on team innovation. Administrative Science Quarterly 51(3): 451-495.

Graziano WG and Tobin RM (2009) Agreeableness. In Leary MR and Hoyle RH (eds) Handbook of Individual Differences in Social Behavior. New York: Guilford Press, 46-61.

Grensing-Pophal L (2001) High-maintenance employees. HR Magazine 46(2): 86-91.

Hackman JR and Oldham GR (1975) Development of the Job Diagnostic Survey. Journal of Applied Psychology 60(2): 159-170.

Hackman JR and Oldham GR (1976) Motivation through the design of work: Test of a theory. 
Organizational Behavior and Human Performance 16(2): 250-279.

Hershberger SL, Lichtenstein P and Knox SS (1994) Genetic and environmental influences on perceptions of organizational climate. Journal of Applied Psychology 79(1): 24-33.

Jackson CL, Colquitt JA, Wesson MJ and Zapata-Phelan CP (2006) Psychological collectivism: A measurement validation and linkage to group member performance. Journal of Applied Psychology 91(4): 884-899.

James LA and James LR (1989) Integrating work environment perceptions: Explorations into the measurement of meaning. Journal of Applied Psychology 74(5): 739-751.

James LR, Choi CC, Ko CHE, McNeil PK, Minton MK, Wright MA and Kim K (2008) Organizational and psychological climate: A review of theory and research. European Journal of Work and Organizational Psychology 17(1): 5-32.

James LR, Gent MJ, Hater JJ and Coray KE (1979) Correlates of psychological influence: An illustration of the psychological climate approach to work environment perceptions. Personnel Psychology 32(3): 563-588.

James LR, Hater JJ, Gent MJ and Bruni JR (1978) Psychological climate: Implications from cognitive social learning theory and interactional psychology. Personnel Psychology 31(4): 783-813.

James LR, James LA and Ashe DK (1990) The meaning of organizations: The role of cognition and values. In Schneider B (ed) Organizational Climate and Culture. San Francisco: Jossey-Bass, 40-84.

James LR and Jones AP (1980) Perceived job characteristics and job satisfaction: An examination of reciprocal causation. Personnel Psychology 33(1): 97-135.

James LR and Tetrick LE (1986) Confirmatory analytic tests of three causal models relating job perceptions to job satisfaction. Journal of Applied Psychology 71(1): 77-82. Janssen O (2000) Job demands, perceptions of effort-reward fairness and innovative work 
behavior. Journal of Occupational and Organisational Psychology 73(3): 287-302.

Janssen O (2001) Fairness perceptions as a moderator in the curvilinear relationships between job demands, and job performance and job dissatisfaction. Academy of Management Journal 44(5): 1039-1050.

Janssen O and van Yperen NW (2004) Employees' goal orientations, the quality of leader-member exchange, and the outcomes of job performance and job satisfaction. Academy of Management Journal 47(3): 368-384.

Jaw BS and Liu W (2003) Promoting organizational learning and self-renewal in Taiwanese companies: The role of HRM. Human Resource Management 42(3): 223-241.

Judge TA and Ilies R (2002) Relationship of personality to performance motivation: A meta-analytic review. Journal of Applied Psychology 87(4): 797-807.

Kitchen PJ and Daly F (2002) Internal communication during change management. Corporate Communications: An International Journal 7(1): 46-53.

Langfred CW (2000) The paradox of self-management: Individual and group autonomy in work groups. Journal of Organizational Behavior 21(5): 563-585.

LeBreton JM, Wu J and Bing MN (2009) The truth(s) on testing for mediation in the social and organizational sciences. In Lance CE and Vandenberg RJ (eds) Statistical and Methodological Myths and Urban Legends: Doctrine, Verity, and Fable in the Organizational and Social Sciences. New York, NY: Routledge, 107-141.

LePine JA and Van Dyne L (2001) Voice and cooperative behavior as contrasting forms of contextual performance: Evidence of differential relationships with Big Five personality characteristics and cognitive ability. Journal of Applied Psychology 86(2): 326-336.

Leung K (1997) Negotiation and reward allocations across cultures. In Early PC and Erez M (eds) New Perspectives on International Industrial and Organizational Psychology. 
San Francisco, CA: New Lexington, 640-675.

Leung K and Brew F (2009) A cultural analysis of harmony and conflict: Toward an integrated model of conflict styles. In Wyer RS, Chiu CY and Hong YY (eds) Understanding Culture: Theory, Research, and Application. New York, US: Psychology Press, 411-428.

Leung K, Brew FP, Zhang ZX and Zhang Y (2011) Harmony and conflict: A cross cultural investigation in China and Australia. Journal of Cross Cultural Psychology 42(5): 795-618.

Leung K, Koch PT and Lu L (2002) A dualistic model of harmony and its implications for conflict management in Asia. Asia Pacific Journal of Management 19(2-3): 201-220.

Lim LL (2009) The influences of harmony motives and implicit beliefs on conflict styles of the collectivist. International Journal of Psychology 44(6): 401-409.

Little TD, Cunningham WA and Shahar G (2002) To parcel or not to parcel: Exploring the question, weighing the merits. Structural Equation Modeling 9(2): 151-173.

MacKinnon DP (2008) Introduction to Statistical Mediation Analysis. New York: Lawrence Erlbaum Associates and Taylor Francis Group LLC.

MacKinnon DP, Fairchild AJ and Fritz MS (2007) Mediation analysis. Annual Review of Psychology 58: 593-614.

MacKinnon DP, Lockwood CM, Hoffman JM, West SG and Sheets V (2002) A comparison of methods to test mediation and other intervening variable effects. Psychological Methods 7(1): 83-104.

Maurer TJ, Weiss EM and Barbeite FG (2003) A model of involvement in work-related learning and development activity: The effects of individual, situational, motivational, and age variables. Journal of Applied Psychology 88(4): 707-724.

May DR, Gilson RL and Harter LM (2004) The psychological conditions of meaningfulness, 
safety and availability and the engagement of the human spirit at work. Journal of Occupational and Organizational Psychology 77(1): 11-37.

Morgeson FP, Delaney-Klinger K and Hemingway MA (2005) The importance of job autonomy, cognitive ability, and job-related skill for predicting role breadth and job performance. Journal of Applied Psychology, 90(2): 399-406.

Morrison EW and Milliken FJ (2000) Organizational silence: A barrier to change and development in a pluralistic world. Academy of Management Review 25(4): 706-31.

Organ DW and Ryan K (1995) A meta-analytic review of attitudinal and dispositional predictors of organizational citizenship behavior. Personnel Psychology 48(4): 775-802.

Parker CP, Baltes BB, Young SA, Huff JW, Altmann RA, Lacost HA and Roberts JE (2003) Relationships between psychological climate perceptions and work outcomes: A meta-analytic review. Journal of Organizational Behavior 24(4): 389-416.

Parzefall MR and Kuppelwieser VG (2012) Understanding the antecedents, the outcomes and the mediating role of social capital: An employee perspective. Human Relations 65(4): 447-472.

Pfeffer J (1994) Competitive Advantage through People: Unleashing the Power of the Workforce. Boston: Harvard Business School Press.

Pierce JL, Newstrom JW, Dunham RB and Barber AE (1989) Alternative Work Schedules. Boston: Allyn \& Bacon.

Preacher KJ and Hayes AF (2004) SPSS and SAS procedures for estimating indirect effects in simple mediation models. Behavior Research Methods, Instruments, and Computers 36(4): 717-731.

Preacher KJ and Hayes AF (2008) Asymptotic and resampling strategies for assessing and comparing indirect effects in multiple mediator models. Behavior Research Methods 40(3): 879-891. 
Preacher KJ, Rucker DD and Hayes AF (2007) Addressing moderated mediation hypotheses: Theory, methods, and prescriptions. Multivariate Behavioral Research 42(1): 185-227.

Rahim MA (1985) A strategy for managing conflict in complex organizations. Human Relations 38(1): 81-89.

Rousseau DM and Fried Y (2001) Location, location, location: Contextualizing organizational research. Journal of Organizational Behavior 22(1): 1-13.

Schmidt AM and DeShon RP (2010) The moderating effects of performance ambiguity on the relationship between self-efficacy and performance. Journal of Applied Psychology 95(3): $572-581$.

Schneider B, Ehrhart MG and Macey WH (2011) Perspectives on organizational climate and culture. In Zedeck S (ed) APA Handbook of Industrial and Organizational Psychology, vol 1. Washington, DC: American Psychological Association, 373-414.

Schneider B, Ehrhart MG, Mayer DM, Saltz JL and Niles-Jolly K (2005) Understanding organizational-customer links in service settings. Academy of Management Journal 48(6): 1017-1032.

Scott SG and Bruce RA (1994) Determinants of innovative behavior: A path model of individual innovation in the workplace. Academy of Management Journal 37(3): $580-607$.

Shalley CE, Gilson LL and Blum TC (2000) Matching creativity requirements and the work environment: Effects on satisfaction and intentions to leave. Academy of Management Journal 43(2): 215-223.

Shrout PE and Bolger N (2002) Mediation in experimental and nonexperimental studies: New procedures and recommendations. Psychological Methods 7(4): 422-445.

Siemsen E, Roth AV, Balasubramanian S and Anand G (2009) The influence of psychological safety and confidence in knowledge on employee knowledge sharing. Manufacturing \& 
Service Operations Management 11(3): 429-447.

Snyder M and Ickes W (1985) Personality and social behavior. In Aronson E and Lindzey G (eds) Handbook of Social Psychology. New York: Random House, 248-305.

Spreitzer GM (1995) Psychological empowerment in the workplace: Dimensions, measurement, and validation. Academy of Management Journal 38(5): 1442-1465.

Staw BM and Ross J (1985) Stability in the midst of change: A dispositional approach to job attitudes. Journal of Applied Psychology 70(3): 469-480.

Taylor SG, Bedeian AG and Kluemper DH (2012) Linking workplace incivility to citizenship performance: The combined effects of affective commitment and conscientiousness. Journal of Organizational Behavior 33(7): 878-893.

Tierney P (1999) Work relations as a precursor to a psychological climate for change. Journal of Organizational Change Management 12(2): 120-133.

Tynan R (2005) The effects of threat sensitivity and face giving on dyadic psychological safety and upward communication. Journal of Applied Social Psychology 35(2): 223-247.

Wang P and Rode JC (2010) Transformational leadership and follower creativity: The moderating effects of identification with leader and organizational climate. Human Relations 63(8): 1105-1128.

Wei YC, Han TS and Hsu IC (2010) High-performance HR practices and OCB: A cross-level investigation of a causal path. The International Journal of Human Resource Management 21(10): 1631-1648.

Wiesenfeld BM, Raghuram S and Garud R (2001) Organizational identification among virtual workers: The role of need for affiliation and perceived work-based social support. Journal of Management 27(2): 213-229.

Zhao X, Lynch JG Jr and Chen Q (2010) Reconsidering Baron and Kenny: Myths and truths about mediation analysis. Journal of Consumer Research 37(2): 197-206. 


\section{Endnotes}

${ }^{1}$ We thank an anonymous reviewer and the action editor for this suggestion.

${ }^{2}$ We thank an anonymous reviewer for this suggestion. 
Table 1 Means, standard deviations, correlations, and reliabilities

\begin{tabular}{|c|c|c|c|c|c|c|c|c|c|c|c|c|}
\hline Variables & Mean & $S D$ & 1 & 2 & 3 & 4 & 5 & 6 & 7 & 8 & 9 & 10 \\
\hline 1 Gender $^{a}$ & 0.56 & 0.50 & - & & & & & & & & & \\
\hline $2 \mathrm{Age}^{\mathrm{b}}$ & 2.32 & 0.65 & -.11 & - & & & & & & & & \\
\hline 3 Organisational tenure ${ }^{c}$ & 2.02 & 0.83 & -.07 & $.30^{* *}$ & - & & & & & & & \\
\hline 4 Education ${ }^{d}$ & 3.62 & 0.73 & -.04 & .11 & -.01 & - & & & & & & \\
\hline 5 Data source $e^{e}$ & 0.37 & 0.49 & $.20^{* *}$ & -.01 & .02 & -.06 & - & & & & & \\
\hline 6 Harmony enhancement & 3.72 & 0.47 & -.04 & .02 & -.01 & -.05 & -.03 & (.68) & & & & \\
\hline 7 Disintegration avoidance & 3.07 & 0.67 & .07 & .00 & -.07 & -.04 & -.08 & $.16^{*}$ & $(.73)$ & & & \\
\hline 8 Psychological climate for communication safety & 3.87 & 1.03 & .03 & -.07 & .09 & -.06 & .04 & $.23^{* *}$ & .00 & $(.71)$ & & \\
\hline 9 Job autonomy & 3.90 & 1.40 & -.04 & .01 & .02 & -.07 & -.06 & .03 & $-.15^{*}$ & .03 & $(.72)$ & \\
\hline 10 Innovative performance & 4.78 & 0.85 & .10 & .10 & $.24^{* *}$ & .06 & .01 & .03 & .00 & $.15^{*}$ & -.03 & $(.86)$ \\
\hline
\end{tabular}

Note: $N=193$. Reliabilities are in parentheses. ${ }^{*} p<.05 ; \quad{ }^{* *} p<.01$.

${ }^{\text {a }}$ Gender: $0=$ female, $1=$ male

${ }^{\mathrm{b}}$ Age: $1=$ lower than 20, $2=20-29,3=30-39,4=40-49,5=$ higher than 49

${ }^{\mathrm{c}}$ Organisation tenure: $1=$ lower than 1 year, $2=1-3$ years, $3=4-6$ years, $4=7-8$ years, $5=9-10$ years, $6=$ higher than 10 years

${ }^{\mathrm{d}}$ Education: 1 = primary school, 2 = middle school, 3 = junior college, 4 = university, 5 = research degree or higher

${ }^{\mathrm{e}}$ Data source: $0=$ Part-time MBA students, $1=$ industrial park employees 
Table 2 Hierarchical regression analysis for the mediating effects of psychological climate for communication safety on the relationships between interpersonal harmony and innovative performance

\begin{tabular}{lccc}
\hline & $\begin{array}{c}\text { Psychological climate for } \\
\text { Cariables }\end{array}$ & \multicolumn{2}{c}{ Innovative performance } \\
\cline { 3 - 4 } Organisational tenure a & .05 & Step 1 & Step 2 \\
Harmony enhancement & $.19^{* *}$ & $.20^{* *}$ & $.20^{* *}$ \\
Disintegration avoidance & .02 & -.01 & -.04 \\
Psychological climate for & & & -.02 \\
communication safety & & & $.14^{*}$ \\
$F$ & $2.61^{*}$ & $2.71^{*}$ & $3.03^{*}$ \\
$R^{2}$ & .04 & .04 & .06 \\
$\Delta R^{2}$ & & & $.02^{*}$ \\
\hline
\end{tabular}

Bias corrected $95 \%$ confidence interval ${ }^{\mathrm{b}}$

\begin{tabular}{lcc} 
& Upper & Lower \\
\hline Harmony enhancement & .1324 & .0022 \\
Disintegration avoidance & .0417 & -.0271 \\
\hline
\end{tabular}

Note: $N=193$. Standardized beta coefficients are presented.

${ }^{\text {a }}$ Organisation tenure: $1=$ lower than 1 year, $2=1-3$ years, $3=4-6$ years, $4=7-8$ years, $5=$ $9-10$ years, $6=$ higher than 10 years

b 5,000 bootstrap samples were employed.

${ }^{*} p<.05 ; \quad{ }^{* *} p<.01$. 
Table 3 Hierarchical regression analysis for the moderating effects of job autonomy on the relationships between interpersonal harmony and psychological climate for communication safety

\begin{tabular}{lccc}
\hline & \multicolumn{2}{c}{ Psychological climate for communication safety } \\
\cline { 2 - 4 } Variables & Step 1 & Step 2 & Step 3 \\
\hline Organisational tenure ${ }^{\mathrm{a}}$ & .05 & .05 & .07 \\
Harmony enhancement & $.19^{* *}$ & $.19^{* *}$ & $.19^{* *}$ \\
Disintegration avoidance & .02 & .02 & .04 \\
Job autonomy & & .03 & .01 \\
Harmony enhancement $\times$ Job autonomy & & \multicolumn{2}{c}{$-.16^{*}$} \\
Disintegration avoidance $\times$ Job autonomy & & $.16^{*}$ \\
$F$ & $2.61^{*}$ & 1.98 & $2.77^{*}$ \\
$R^{2}$ & .04 & .04 & .08 \\
$\Delta R^{2}$ & & .00 & $.04^{*}$ \\
\hline
\end{tabular}

Note: $N=193$. Standardized beta coefficients are presented.

a Organisation tenure: $1=$ lower than 1 year, $2=1-3$ years, $3=4-6$ years, $4=7-8$ years, $5=$ 9-10 years, $6=$ higher than 10 years

${ }^{*} p<.05 ; \quad{ }^{* *} p<.01$. 


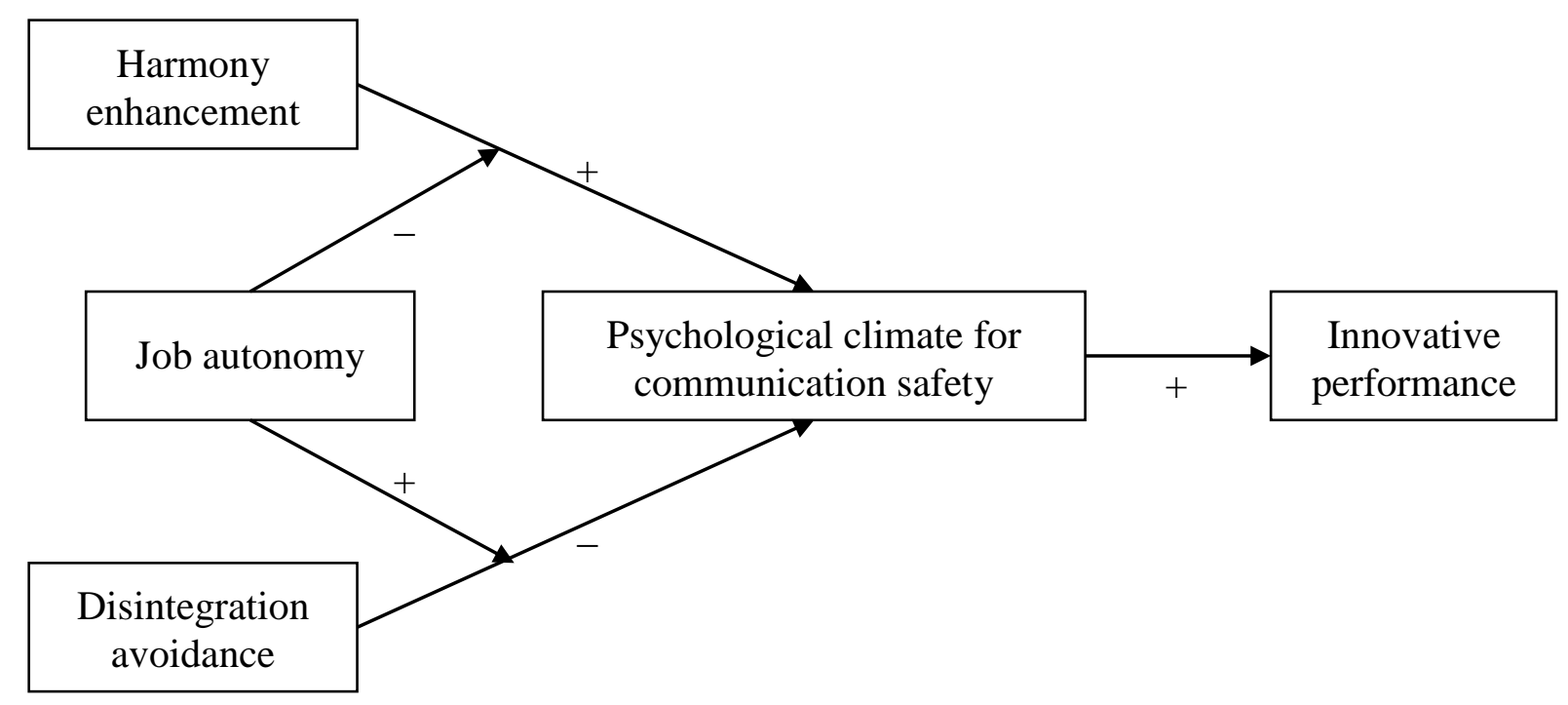

Figure 1 The proposed model for the study. 


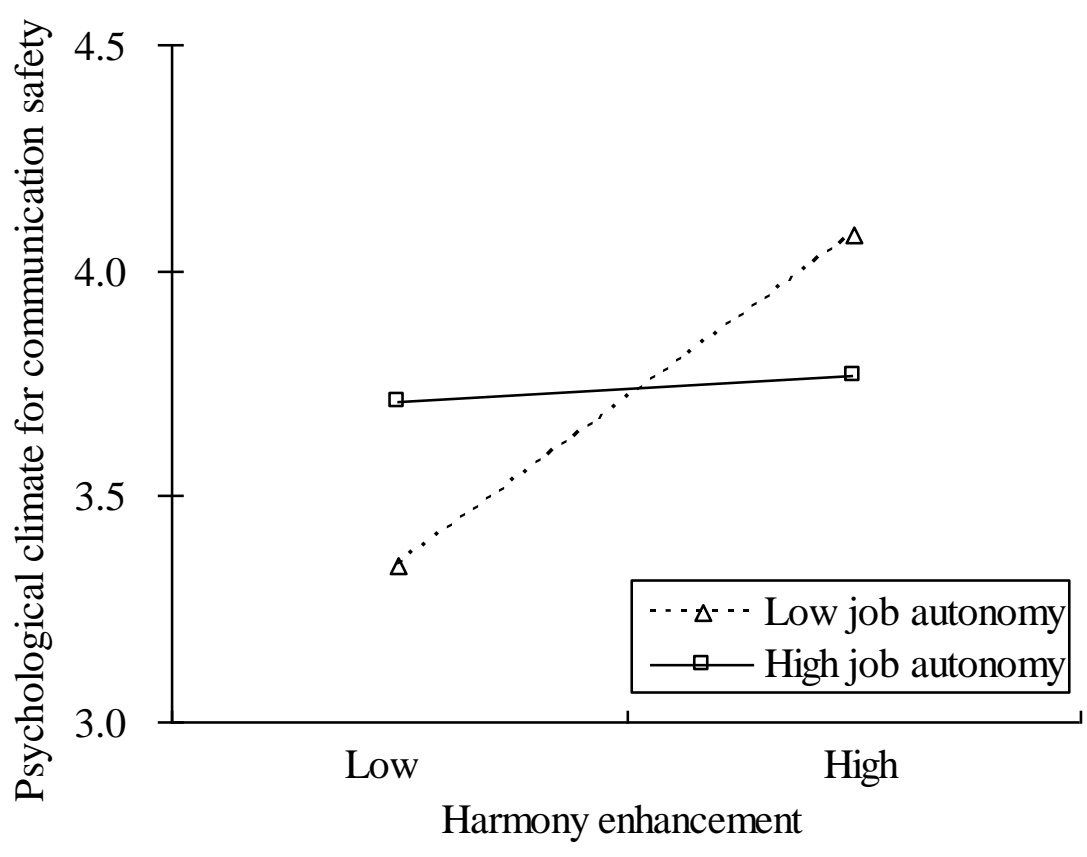

Figure 2a Interaction effect of harmony enhancement and job autonomy on psychological climate for communication safety.

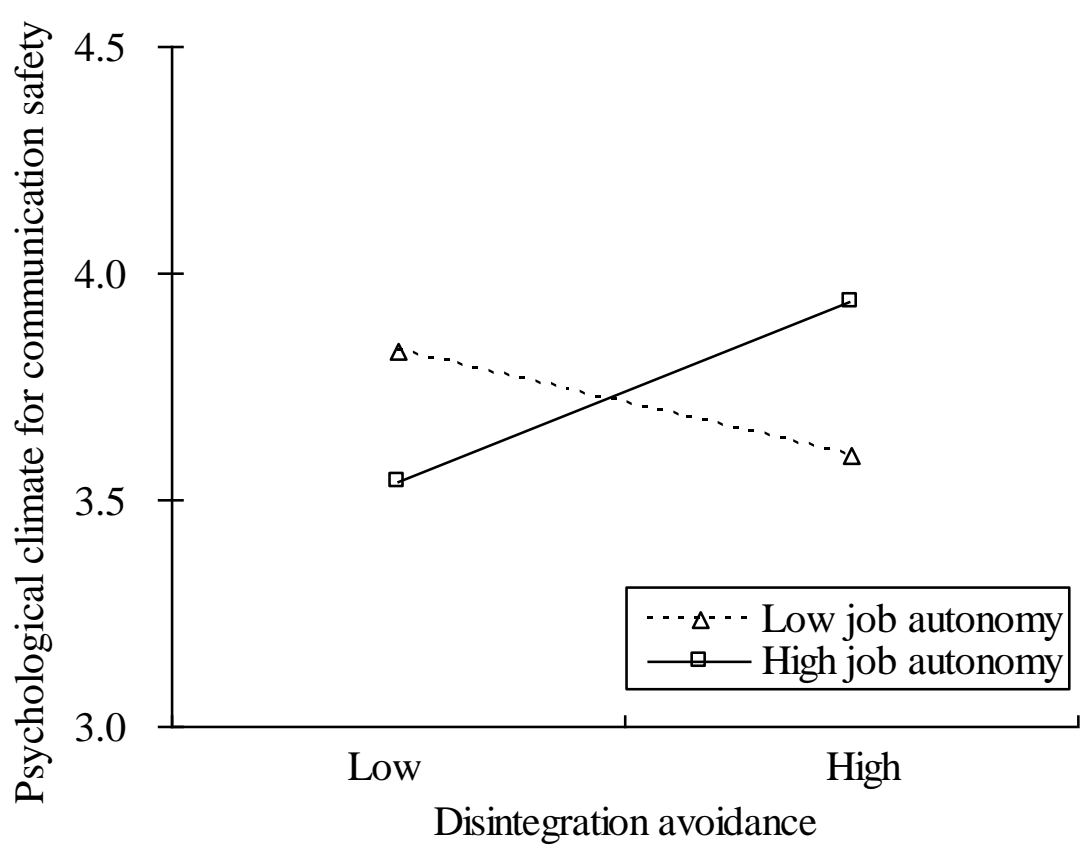

Figure 2b Interaction effect of disintegration avoidance and job autonomy on psychological climate for communication safety. 
Appendix The interpersonal harmony items

\section{Harmony enhancement}

1. As a consequence of maintaining harmony between people, you are able to broaden your view of the world.

2. Having an ability to interact with others harmoniously is vital for achieving major successes.

3. The idea that interpersonal harmony promotes wealth is a wise one.

4. Maintaining interpersonal harmony is an important goal in life.

5. Making concessions demonstrates your maturity and capacity for forgiveness.

6. Everything prospers when there is harmony in the family; maintaining harmony among family members is very important.

7. If there is no need for forced consensus and everyone has different perspectives, then everyone should be willing to compromise.

8. Being patient and willing to compromise is a show of respect to the other person.

9. It is a virtue to tolerate everything.

10. In interpersonal interactions, you should be considerate of others' difficulties and forgive them whenever possible.

11. Being patient and willing to compromise indicates that a person is gracious and forgiving. 12. Being patient and willing to compromise demonstrates that you have a higher sense of self-discipline than ordinary people.

13. Compromise is a type of wisdom as well as a virtue. *

14. A group can only sustain its progress in a harmonious environment. *

15. Interpersonal harmony is an important goal to achieve in life. *

16. For the collective good, it's necessary to strive for consensus and harmony with those who hold different viewpoints while acknowledging the differences. *

\section{Disintegration avoidance}

17. If a person does you favours, you must be tolerant with them in order to protect your own interests.

18. When people are in a more powerful position than you, you should treat them in an accommodating manner.

19. If your losses are going to be small, there is no need to fight to the end.

20. As you often have to ride with the tide, it is better not to worry about what is unacceptable or unfair.

21. You should not disturb your harmonious relationships with others, in order that embarrassment is avoided in future encounters.

22. Interacting harmoniously with people prevents them from giving you trouble in the future.

23. To avoid retaliation from others, we should refrain from offending others. *

24. Maintaining a harmonious relationship with people in power can bring a lot of benefits. *

25 . Fighting with others can easily bring more loss than gain. *

Note: * Items were newly developed for this study. 